(c) 2017, THE AUTHORS. Published by FASS and Elsevier Inc. on behalf of the American Dairy Science Association ${ }^{\circledR}$. This is an open access article under the CC BY-NC-ND license (http://creativecommons.org/licenses/by-nc-nd/3.0/).

\title{
Hexanal as biomarker for milk oxidative stress induced by copper ions
}

\author{
Mohammad Asaduzzaman, ${ }^{*}$ Franco Biasioli, $\uparrow$ Maria Stella Cosio, $\ddagger$ and Matteo Schampicchio*1 \\ *Faculty of Science and Technology, Free University of Bozen-Bolzano, Piazza Università 1, 39100 Bolzano, Italy \\ †Department of Food Quality and Nutrition, Research and Innovation Centre, Fondazione Edmund Mach (FEM), via E. Mach 1, \\ 38010 San Michele all'Adige (TN), Italy \\ ‡Department of Food, Environment and Nutritional Sciences, Universita degli Studi di Milano, Via Mangiagalli 25, 20133 Milano, Italy
}

\begin{abstract}
Milk flavor varies greatly due to oxidative stress during storage. Several studies have documented the use of volatile biomarkers for determining milk oxidation, but only a few have focused on the development of inline procedures enabling the monitoring of milk oxidative stress. In this work, oxidative stress was induced in pasteurized milk samples by spiking increasing concentrations of copper ions (from 0 to $32 \mathrm{mg} \cdot \mathrm{L}^{-1}$ ). During storage $\left(4^{\circ} \mathrm{C}\right)$, hexanal evolution was monitored by a proton transfer reaction mass spectrometer. The mass fragment $m / z 83$ was selected as a biomarker for hexanal determination. Its intensity evolved with a sigmoidal trend, showing a maximum rate proportional to the $\mathrm{Cu}^{2+}$ content in milk. The proposed approach is simple, fast (up to $120 \mathrm{sample} / \mathrm{h}$ ), sensitive $\left(8.8 \mu \mathrm{g} \cdot \mathrm{m}^{-3}\right.$ per $\mu M$ hexanal in the sample), with low limit of detection (0.5 $\mu M$, determined as 3 times the standard deviation divided by the slope of a calibration line), precise $(<6 \%)$, with good recovery (99-104\%), and noninvasive. The method can be used for laboratory screening of milk susceptibility toward oxidation or for quality control in the processing line.
\end{abstract}

Key words: milk oxidation, copper, hexanal, proton transfer reaction mass spectrometer

\section{INTRODUCTION}

Milk flavor varies greatly depending on its oxidative state. Oxidation of milk can cause oxidized flavor for several reasons, such as the oxidation of unsaturated lipids induced by metal ions, or even initiated by the presence of active oxygen species, light, or enzymes (Amamcharla and Metzger, 2014).

Metal ions are well known to catalyze lipid peroxidation and induce oxidative stress (Berton-Carabin et al., 2014; Scheidegger et al., 2016). These events cause several drawbacks such as shorter shelf life, off-flavor

Received May 4, 2016.

Accepted November 7, 2016.

${ }^{1}$ Corresponding author: matteo.scampicchio@unibz.it development, and altered nutritional values (Havemose et al., 2007). Copper, as well as other metal ions, can catalyze such events through the formation of hydroperoxides that are precursors of secondary oxidation products, such as aldehydes, hydrocarbons, and ketones (Jenq et al., 1988; Buettner and Jurkiewicz, 1996; Havemose et al., 2006). Among these, hexanal is one of the most studied volatile biomarkers for milk oxidative stress. Several studies have reported that it evolves during the oxidation of UFA, such as CLA (Sanches-Silva et al., 2004; Garcia-Llatas et al., 2007; Panseri et al., 2011; Correddu et al., 2015).

Several sensory and analytical methods have been developed for detecting one or more members of the aldehyde family. These include sensory analysis (Hedegaard et al., 2006), olfactometry (d'Acampora Zellner et al., 2008), and gas chromatography (Havemose et al., 2007). However, due to their complexity, time of analysis, and costs, implementation of these methods in food industries for quality control is often limited. Instead, there is a great interest in rapid, specific, and highly sensitive methods able to detect or monitor the evolution of oxidation phenomena in milk and dairy products (Fabris et al., 2010).

Recently, proton transfer reaction mass spectrometry (PTR-MS) has been proposed as an innovative analytical instrument for food quality control (Biasioli et al., 2011; Cappellin et al., 2013). Proton transfer reaction mass spectrometry belongs to the so-called soft ionization methods, where a very limited fragmentation of the product ion is generated, ideally limited by the nominal mass. Proton transfer reaction mass spectrometry is based on the direct injection of volatile organic compounds (VOC) into a drift tube, where protonated water $\left(\mathrm{H}_{3} \mathrm{O}^{+}\right)$reacts with VOC under soft ionization conditions. Air is generally used as the carrier gas. The subsequent detection signal is related to the amount of protonated molecules (Lindinger et al., 1998) as follows:

$$
\mathrm{H}_{3} \mathrm{O}^{+}+\mathrm{VOC} \rightarrow \mathrm{VOC} \cdot \mathrm{H}^{+}+\mathrm{H}_{2} \mathrm{O} .
$$

The advantages of this instrument over traditional gas chromatography techniques is the limited sample han- 
dling. Proton transfer reaction mass spectrometry is easy to operate, very fast, highly sensitive, and nondestructive. Also, no sample preparation is necessary because the headspace of a sample is simply and directly injected into the detector.

Several attempts have been reported to apply PTRMS technique in dairy products. Examples include the classification of butter and butter oil (Van Ruth et al., 2008), the identification of the geographical origin of butter (Macatelli et al., 2009), and the monitoring of the effect of photo-oxidation of milk (Beauchamp et al., 2014). Further works have focused on the monitoring of VOC during milk light exposure (Zardin et al., 2016), milk storage (Silcock et al., 2014), lactic fermentation (Soukoulis et al., 2010), yogurt starters (Gallardo-Escamilla et al., 2005), and finally, cheese aging (Aprea et al., 2007). However, to date no studies have been carried out to evaluate the application of PTR-MS technique to monitor the autoxidation of milk during storage.

The aim of this work was to set up a method based on PTR-MS to determine hexanal content in pasteurized milk samples and to monitor its content on milk having different oxidative states. For such a purpose, pasteurized milk samples were spiked with increasing concentrations of copper to induce increasing oxidative stress. The resulting evolution profile of hexanal was determined by PTR-MS during storage conditions $\left(4^{\circ} \mathrm{C}\right)$ and the resulting experimental observations fitted with a modified Gompertz model (Cuenca et al., 2016) to compare the effect of the increasing oxidative stress of milk on the resulting evolution of hexanal. Overall, the present work provides evidence of the usefulness of PTR-MS to evaluate the oxidation state of milk samples.

\section{MATERIALS AND METHODS}

\section{Materials}

The materials used were hexanal standard (SigmaAldrich, Germany), copper (II) sulfate (Sigma-Aldrich, Hamburg, Germany), milli-Q water (Merck Millipore, UK), and pasteurized whole milk, skim milk $(0.3 \%$ fat), and partial skim milk (1.8\% fat; Mila Südtirol, Bolzano, Italy).

\section{Milk Sample Preparation}

Fresh chilled pasteurized whole milk (3.5\% fat and $3.8 \%$ protein) was received from a local producer (Mila Südtirol) and analyzed by a local milk federation (Sennereiverband Südtirol, Bolzano, Italy) that declared a copper content below $0.2 \mathrm{mg} \cdot \mathrm{L}^{-1}$. To this milk sample, copper (II) sulfate was added to reach a final concentration of $2,4,8,16$, and $32 \mathrm{mg} \cdot \mathrm{L}^{-1}$ of copper ions $\left(\mathrm{Cu}^{2+}\right)$. For each concentration, 18 samples were prepared by transferring $2 \mathrm{~mL}$ of milk sample in 40-mL glass vials fitted with polyterafluoroethylene screw-cap septa (VILEP, Milan, Italy). All the samples were stored at $4.0 \pm 0.3^{\circ} \mathrm{C}$ for $10 \mathrm{~d}$. The headspace was analyzed at $0,2,4,6,8$, and $10 \mathrm{~d}$ of storage.

\section{Headspace Volatile Analysis Using PTR-MS}

The headspace analysis was performed by using a commercial high-sensitivity PTR-MS (Ionicon, Analytik GmbH, Innsbruck, Austria). The sample were first incubated in vials at $30^{\circ} \mathrm{C}$ for $30 \mathrm{~min}$. Then, the vial headspace was then transferred at a flow rate of 45 $\mathrm{mL} \cdot \mathrm{min}^{-1}$ through a heated $\left(80^{\circ} \mathrm{C}\right)$ capillary inlet system $\left(1 / 16^{\prime \prime}\right.$, outer diameter) directly into the drift tube of the PTR-MS. The headspace was replaced by clean air by passing through an activated charcoal filter.

The instrument was operated in mass scan mode over an $m / z$ range of 21 to 200 with a dwell time of $100 \mathrm{~ms}$ per $m / z$, which resulted in total scan time of about 20 s per cycle. The PTR-MS drift tube was maintained at $550 \mathrm{~V}, 2.03 \times 10^{2} \mathrm{~Pa}$, and $80^{\circ} \mathrm{C}$. The signals recorded by PTR-MS are count rate $\left(c_{R H^{+}}\right)$over the $m / z$ range. Count rates are normalized with respect to the $m / z 21$, which arises from the ${ }^{18} \mathrm{O}$ substituted isotopologue of hydronium $\left(\mathrm{H}_{3} \mathrm{O}^{+}\right)$. Because the natural ratio between $\mathrm{m} / z 19\left[\mathrm{H}_{3}{ }^{16} \mathrm{O}^{+}\right]$and $m / z 21\left[\mathrm{H}_{3}{ }^{18} \mathrm{O}^{+}\right]$is about $500: 1$, the $m / z 21$ signal was multiplied by 500 to estimate the abundance of hydronium ions $\left(\mathrm{cps}_{\mathrm{H}_{3}{ }^{18} \mathrm{O}^{+}}\right)$. To calculate the VOC concentration $\left(\mu \mathrm{g} \cdot \mathrm{m}^{-3}\right)$ from count rate (cps), the following equation was used (Lindinger et al., 1998):

$$
[R]_{p p b v}=\frac{c p s_{R H^{+}}}{c p s_{H_{3}{ }^{18} O^{+}}} \cdot \frac{10^{9}}{500} \cdot \frac{K}{k} \cdot \frac{T}{P} \cdot \frac{1}{t},
$$

where cps $_{R H^{+}}$is the count per second of the ionized analyte $\left(\mathrm{RH}^{+}\right)$and $\mathrm{cps}_{\mathrm{H}_{3}^{18} \mathrm{O}^{+}}$is the count rate for the $\mathrm{m} / z 21 ; K$ is Boltzmann constant; $k$ is the rate constant $\left(2 \times 10^{-9} \mathrm{~cm}^{3} \cdot \mathrm{s}^{-1}\right)$ of the protonation reaction; $T, P$, and $t$ are, respectively, the temperature $(353 \mathrm{~K})$, pressure $\left(2.03 \times 10^{2} \mathrm{~Pa}\right)$, and average reaction time $(85 \mu \mathrm{s})$ in the drift tube; and $10^{9}$ is a conversion factor to express the result in $\mu \mathrm{g} \cdot \mathrm{m}^{-3}$.

The signal of each sample is determined as average of 5 consecutive scan cycles, a part of the first cycle that was always disregarded. Each sample measurement was repeated in triplicate. 


\section{Data Analysis}

The limit of detection (LOD) was determined as LOD $=3 s / b$, where $b$ is the slope of the calibration line obtained with at least 6 increasing concentrations of hexanal and $s$ is the standard deviation of the calibration line (Olivieri et al., 2006). The precision of the method was expressed as relative standard deviation predicted from 10 replicate measurements at 3 concentrations $(1,5$, and $10 \mu M)$ of hexanal. The accuracy was estimated as the recovery from known concentrations of hexanal solutions $\left(0.4 \mu \mathrm{g} \cdot \mathrm{g}^{-1}\right)$. A modified Gompertz model was applied to describe the evolution of hexanal $([R])$ during milk storage:

$$
\begin{aligned}
{[R] } & =[R]_{0}+\left([R]_{\infty}-[R]_{0}\right) \\
& \times \exp \left\{-\exp \left[\frac{\mu_{\max } e}{[R]_{\infty}-[R]_{0}}(\lambda-t)\right]+1\right\},
\end{aligned}
$$

where $[R]_{0}$ is the initial signal intensity, $[R]_{\infty}$ is the maximum signal intensity, $\mu_{\max }$ is the maximum rate of volatile formation, $\lambda$ is the lag time, $t$ is the time of reaction, and $e$ is the Euler number.

\section{Software}

The conversion of signal intensities to parts per billion by volume (ppbv) was conducted using $\mathrm{R}$ version 3.2.0 (The R Foundation for Statistical Computing, Vienna, Austria). Data normalization and expression of the results were performed by Microsoft Excel (version 2013, Microsoft Corporation, Redmond, WA).

\section{RESULTS}

\section{Determination of Hexanal in Milk by Headspace-PTR-MS}

Proton transfer reaction mass spectrometry is a soft ionization technique that is generally used to quickly analyze the VOC contained in the headspace of sample vials. Ideally, the fragmentation of the precursor ion is absent (Lindinger et al., 1998). Instead, Figure 1 shows that the mass spectra of hexanal $\left(\mathrm{C}_{6} \mathrm{H}_{12} \mathrm{O}-\mathrm{H}^{+}\right)$in milk exhibit 3 main fragments: $m / z 55(100), 83(48)$, and 101(3), where the values in parentheses correspond to the relative percentage intensity respect the most abundant peak (base peak). The base peak has assigned a value of $100 \%$ and all other masses are indicated as a percentage of the base peak. Although the intensities depend on the instrumental settings, the fragmentation pattern is consistent with those reported elsewhere (Pang, 2015).

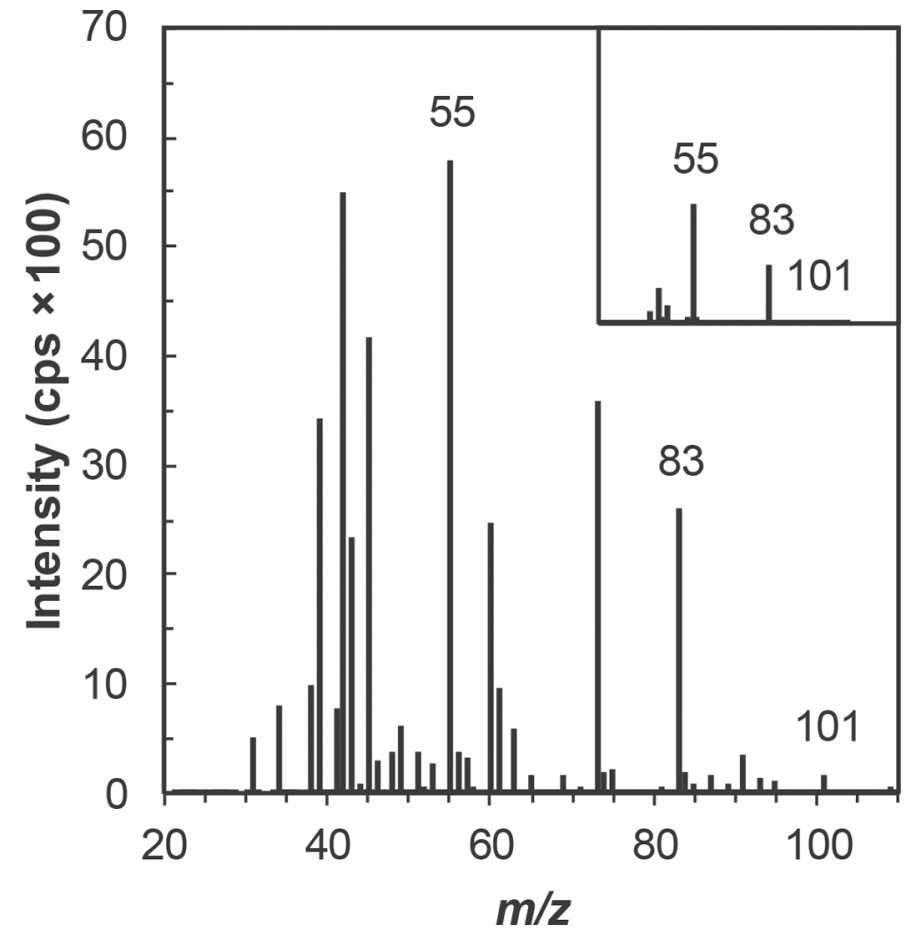

Figure 1. Mass spectra from headspace analysis of milk spiked with hexanal $(5 \mu M)$. Also shown (inset) are the resulting mass spectra obtained after the subtraction of the milk spectra obtained before the addition of hexanal.

Among these fragments, the mass ion $\mathrm{m} / \mathrm{z} 83$ $\left(\mathrm{C}_{5} \mathrm{H}_{10} \mathrm{O}-\mathrm{H}^{+}\right)$was selected as the biomarker for milk oxidative stress. This fragment comes from the loss of a water molecule from the protonated molecular ion. Its choice as biomarker has several advantages. First, its signal intensity is almost negligible in freshly prepared pasteurized milk samples, whereas its intensity starts increasing during storage. Then, the intensity ratio between the isotopes $m / z 83$ and 84 results in 100:6.7, which perfectly matches the theoretical value obtained from the isotopic rule of carbon abundances. Both these observations confirm the absence of interferences.

Instead, the mass ion $m / z 101$, corresponding to the precursor ion of hexanal $\left(\mathrm{C}_{6} \mathrm{H}_{12} \mathrm{O}-\mathrm{H}^{+}\right)$, showed the lowest intensity and was not useful for quantification. Finally, the fragment $m / z 55\left(\mathrm{C}_{4} \mathrm{H}_{6}-\mathrm{H}^{+}\right)$, although its highest intensity $\left(58 \times 10^{2} \mathrm{cps}\right)$, was not used for quantification as its signal was affected by interferences. Interferences of this signal were observed by applying the isotopic rule of carbon abundances to this fragment. Theoretically, the intensity ratio between $\mathrm{m} / z 55$ and 56 isotopes should be 100:4.4. Instead, when hexanal was spiked in water samples, a ratio of 100:5.6 was found. A larger deviation was observed when hexanal was spiked in milk sample (100:6.8). These deviations suggest the concomitant presence of other volatile com- 
ponents contributing to the signal at $\mathrm{m} / \mathrm{z} 55$ and in part attributed to the water cluster $\mathrm{H}_{3} \mathrm{O}^{+}\left(\mathrm{H}_{2} \mathrm{O}\right)$ that is isobaric with the product ion $\mathrm{m} / z 55$ (Pang, 2015). These clusters are typically formed with the PTR-MS when water vapor concentration in the drift tube is too high. A detailed description of this phenomena is reported elsewhere (Jobson and McCoskey, 2010).

\section{Effect of Equilibration Time}

Once the sample is introduced into the vial and the vial is sealed, volatile components contained in the sample diffuse into the gas phase until the headspace has reached a state of equilibrium. For quantitative analysis, the time required to pass from a transient to equilibrium state is of great importance. Figure 2 shows the headspace analysis of water or milk spiked with hexanal $(5 \mu M)$ at different equilibration times (at $30^{\circ} \mathrm{C}$ ). The signal intensity of the mass fragment $\mathrm{m} / \mathrm{z}$ 83 increased with the holding time, until about $30 \mathrm{~min}$. Afterward, the signal intensity reached a plateau value that remained constant even for a longer holding time. However, holding time should be lower than 60 min to minimize potential oxidation of the sample and the formation of volatiles from other reactions. This means that $30 \mathrm{~min}$ is the optimal time required to efficiently partition hexanal into the headspace and it was used in all further experiments.

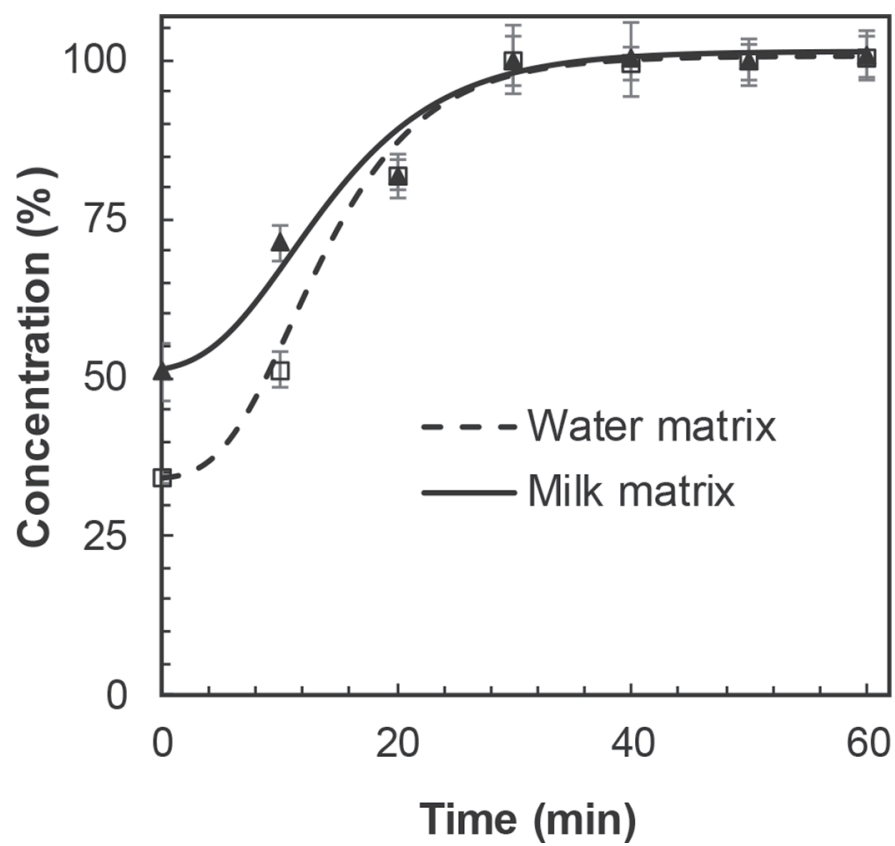

Figure 2. Headspace equilibrium time obtained at $30^{\circ} \mathrm{C}$. Error bars correspond to $\mathrm{SD}(\mathrm{n}=2)$.

\section{Sampling Rate}

Figure 3 shows the transient abundance of the fragment $m / z 83$ in relation to milk samples spiked with increasing concentrations of hexanal (from 0-10 $\mu M$ ). A constant flow of dry air $\left(45 \mathrm{~mL} \cdot \mathrm{min}^{-1}\right)$ is passing continuously through the headspace of the sample, as shown in Figure 3A. As the injection port is opened, the headspace of the sample reaches the mass analyzer in less than $2.5 \mathrm{~s}$ (time from the injection to the detection). Consequently, the signal intensity rises sharply to form a peak. The time required to reach the maximum peak intensity takes about $22.5 \mathrm{~s}$ from the opening of the injection port. Then, the signal fades down as the headspace of the sample becomes depleted. The resulting skewness profile of the signal is typical of a convective dispersion process. Here, this phenomenon is emphasized because of the short residence time. Overall, the time of analysis is $30 \mathrm{~s}$; after that, a further readout can be taken, which allows a rate of analysis up to 120 samples/h.

\section{Analytical Performance}

Figure 3B shows the raw signal intensities (peak height) obtained during the headspace analysis of milk samples spiked with different concentration of hexanal $(1-10 \mu M)$. The samples were measured in triplicate from low to high concentrations and then the order was reversed. From the comparison of the forward and backward analysis, no carryover effect was detected. The results showed that the maximum peak was linearly dependent on the hexanal concentration of the sample $\left(R^{2}=0.999\right)$, with sensitivity of $8.8 \pm 0.4$ $\mu \mathrm{g} \cdot \mathrm{m}^{-3}$ per $\mu M$ hexanal in the sample (determined as slope of the calibration curve) and LOD below $0.5 \mu \mathrm{M}$. The repeatability was determined at 3 concentrations (1, 5, and $10 \mu M$ hexanal in milk), and expressed as relative standard deviation of 10 milk samples. The results were always below $6.5 \%$.

Table 1 compares the analytical performance above with those obtained when hexanal was spiked in water. The comparison of the results shows no significant differences for the coefficients of determination and the precision values. The main difference, instead, regarded the sensitivity values. When hexanal was dissolved in milk samples, the sensitivity halved. Apparently, matrix components co-eluting with hexanal alter the ionization efficiency, resulting in reduced sensitivity.

In addition to the ionization suppression, some components in milk samples can decrease the partition coefficient of hexanal as a result of interactions with milk fats (Kersiene et al., 2008). This was observed 


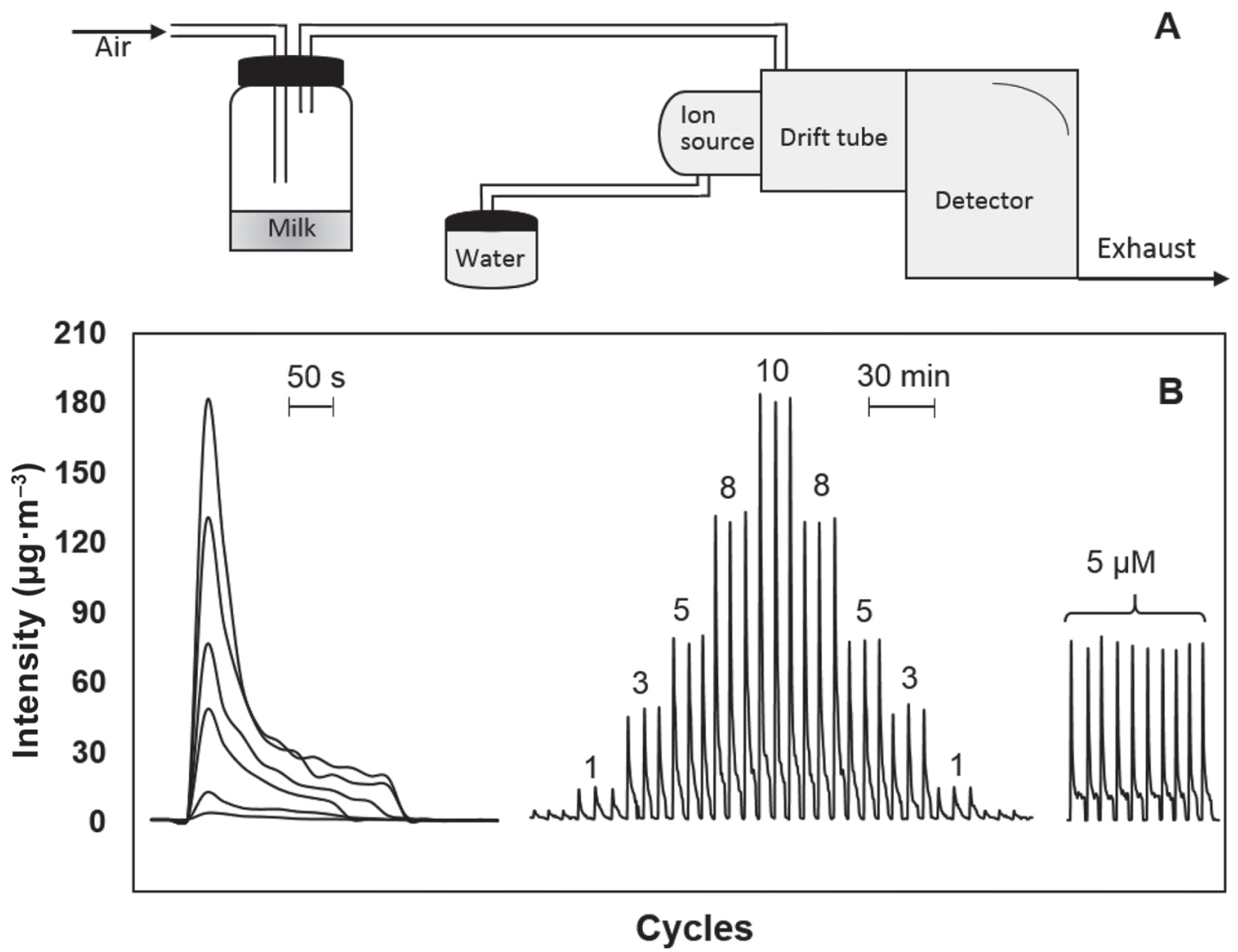

Figure 3. (A) Manifold for detection of hexanal from the milk sample headspace, where volatile organic compounds carried out by air are protonated by $\mathrm{H}_{3} \mathrm{O}^{+}$ions and analyzed by proton transfer reaction mass spectrometer. (B) The left side output shows the transient signal of $m / z$ 83 in relation to the hexanal concentration. The middle shows the calibration run for the series of hexanal standard in a range of 1 to $10 \mu M$, and the right shows 10 repetitive signal intensities for a solution containing $5 \mu M$ hexanal.

experimentally by comparing the sensitivity obtained by spiking increasing concentration of hexanal (from 1 to $10 \mu M)$ into water and pasteurized skim milk $(0.3 \%$ fat), partial skim milk (1.8\% fat), and whole milk (3.5\% fat). The sensitivity values obtained from the slopes of the calibration curves showed the trend: water (19) $>$ skim (18) > partial skim (16) > whole pasteurized milk (9). The value in parentheses is the slope value in $\mu \mathrm{g} \cdot \mathrm{m}^{-3}$ per $\mu M$ hexanal in the sample. As anticipated, the higher fat content reduces the sensitivity of the mass ion $m / z 83$.

\section{Analysis of Hexanal in Milk Samples Under Different Oxidation States}

To test the suitability of the mass ion $m / z 83$ as a biomarker for evaluating milk oxidative stress, pasteurized milk samples were spiked with an increasing concentration of copper ions (from 0 to $32 \mathrm{mg} \cdot \mathrm{L}^{-1}$ ) to induce an increasing oxidation state. The PTR-MS was applied to monitor the evolution of the ion $m / z 83$ during different times of storage, with the samples maintained at the same temperature $\left(4^{\circ} \mathrm{C}\right)$. Figure 4 shows the resulting

Table 1. Analytical parameters for hexanal spiked into water or milk ${ }^{1}$

\begin{tabular}{lccccc}
\hline Matrix & $\begin{array}{c}\text { Sensitivity } \\
\left(\mu \mathrm{g} \cdot \mathrm{m}^{-3} / \mu M\right)\end{array}$ & $\begin{array}{c}\text { Linearity } \\
\left(\mathrm{R}^{2}\right)\end{array}$ & $\begin{array}{c}\text { LOD } \\
(\mu M)\end{array}$ & $\begin{array}{c}\text { Precision } \\
(\%)\end{array}$ & $\begin{array}{c}\text { Recovery } \\
(\%)\end{array}$ \\
\hline Water & $18.5 \pm 0.4$ & 0.999 & 0.2 & $4.8 \pm 0.6$ & 99 \\
Milk & $8.8 \pm 0.4$ & 0.999 & 0.5 & $6.5 \pm 0.8$ & 104 \\
\hline
\end{tabular}

${ }^{1}$ Sensitivity was determined as the slope of the calibration curve. The limit of detection (LOD) was determined as signal to noise ratio of 3 , where the noise was derived from the standard deviation of the calibration plot. Precision is the relative standard deviation \% average of 3 series of $\mathrm{n}$. Ten repetitions each, at 1, 5, and $10 \mu M$ of hexanal. Recovery is determined as relative difference between the milk sample before and after fortification with 2 and $4 \mu M$ of hexanal standard solution. 
Table 2. Fitting parameters of the Gompertz function ${ }^{1}$

\begin{tabular}{lccccc}
\hline $\begin{array}{l}\mathrm{Cu}^{2+} \\
(\mu M)\end{array}$ & $\begin{array}{c}{[R]_{0}} \\
\left(\mu \mathrm{g} \cdot \mathrm{m}^{-3}\right)\end{array}$ & $\begin{array}{c}{[R]_{\infty}} \\
\left(\mu \mathrm{g} \cdot \mathrm{m}^{-3}\right)\end{array}$ & $\begin{array}{c}\mu_{\max } \\
\left(\mu \mathrm{g} \cdot \mathrm{m}^{-3} \cdot \mathrm{d}^{-1} / \mu M\right)\end{array}$ & $\lambda(\mathrm{d})$ & $\mathrm{R}^{2}$ \\
\hline 0 & 3.70 & 1.11 & 1.06 & 3.67 & 0.85 \\
2 & 3.70 & 3.58 & 2.06 & 3.62 & 0.86 \\
4 & 3.70 & 9.47 & 2.46 & 1.92 & 0.91 \\
8 & 3.70 & 22.97 & 3.50 & 1.04 & 0.97 \\
16 & 3.70 & 43.66 & 6.44 & 0.48 & 0.96 \\
32 & 3.70 & 56.83 & 8.70 & 0.38 & 0.96 \\
\hline
\end{tabular}

${ }^{1}[R]_{0}$ is the initial signal intensity, $[R]_{\infty}$ is the maximum signal intensity, and $\lambda$ is the lag time.

evolution profile, where each point is the average signal intensity of 3 independent samples. When copper was not used, the headspace of the milk sample provides a signal with negligible intensity. Instead, when copper was present, the signal intensity increased with an almost sigmoidal trend. For instance, when copper was 32 $\mathrm{mg} \cdot \mathrm{L}^{-1}$, after $6 \mathrm{~d}$ of storage (at $4^{\circ} \mathrm{C}$ ), the signal reached a maximum value of $\sim 60 \mu \mathrm{g} \cdot \mathrm{m}^{-3}$. The experimental points show a sigmoidal profile that was described by a Gompertz fitting function (see equation [3]). Table 2 reports the fitting parameters of the Gompertz function $\left(\lambda,[R]_{\infty}\right.$, and $\left.\mu_{\max }\right)$. The values of these parameters reflect the copper content in milk, and thus, its oxidation state. For instance, at higher oxidation states (i.e., higher concentration of $\mathrm{Cu}^{2+}$ ), the time needed to

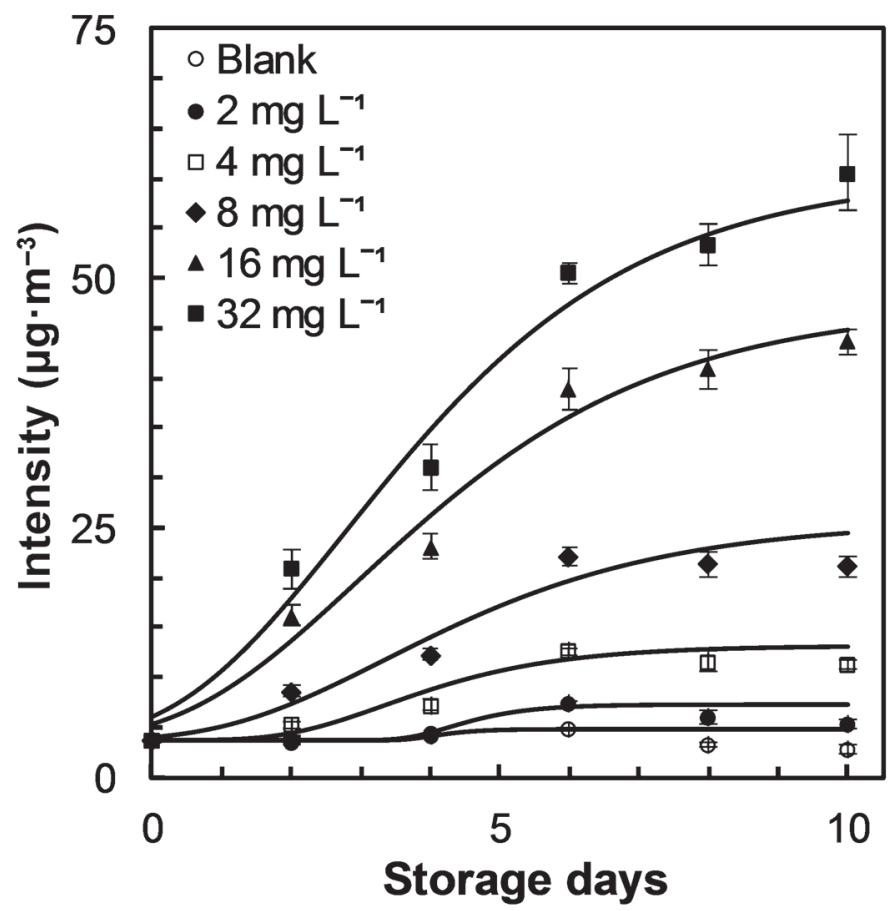

Figure 4. Evolution of hexanal in oxidized milk with different concentration of added $\mathrm{Cu}^{2+}$ and storage at $4^{\circ} \mathrm{C}(\mathrm{m} / z$ 83). Error bars correspond to $\mathrm{SD}(\mathrm{n}=3)$. observe the initial raise of the signal intensity $(\lambda$, lag time) is reduced, the maximum peak intensity $\left([R]_{\infty}\right)$ is increased, together with the rate of formation $\left(\mu_{\max }\right)$. These parameters have practical utility especially for quality control procedures where their monitoring can be used to evaluate the susceptibility of milk to oxidation.

\section{CONCLUSIONS}

The early detection of oxidation in milk is important in the dairy industry. The formation of hexanal due to oxidative change in milk can be monitored using the PTR-MS signal related to hexanal at $m / z$ 83. Addition of $\mathrm{Cu}^{2+}$, as expected from its catalytic effect, showed a positive effect on the oxidation process, which is indicated by the shorter lag time, and the higher rate and greater intensity of signal related to hexanal formation. Overall, this work has demonstrated the utility of PTR-MS technique to determine hexanal content in pasteurized milk samples and to monitor its content on milk having different oxidative states.

\section{ACKNOWLEDGMENTS}

We are grateful to the Province of Bolzano for financial support (Landesregierung mittels Beschluss Nr. $1472,07.10 .2013)$.

\section{REFERENCES}

Amamcharla, J. K., and L. E. Metzger. 2014. Modification of the ferric reducing antioxidant power (FRAP) assay to determine the susceptibility of raw milk to oxidation. Int. Dairy J. 34:177-179.

Aprea, E., F. Biasioli, F. Gasperi, D. Mott, F. Marini, and T. D. Maerk. 2007. Assessment of trentingrana cheese ageing by proton transfer reaction-mass spectrometry and chemometrics. Int. Dairy J. 17:226-234.

Beauchamp, J., E. Zardin, P. Silcock, and P. J. Bremer. 2014. Monitoring photooxidation-induced dynamic changes in the volatile composition of extended shelf life bovine milk by PTR-MS. J. Mass Spectrom. 49:952-958.

Berton-Carabin, C. C., M. Ropers, and C. Genot. 2014. Lipid oxidation in oil-in-water emulsions: Involvement of the interfacial layer. Compr. Rev. Food Sci. Food Saf. 13:945-977.

Biasioli, F., C. Yeretzian, F. Gasperi, and T. D. Maerk. 2011. PTR-MS monitoring of VOC and BVOCs in food science and technology. TRAC-Trends in Analytical Chemistry 30:968-977.

Buettner, G., and B. Jurkiewicz. 1996. Catalytic metals, ascorbate and free radicals: Combinations to avoid. Radiat. Res. 145:532-541.

Cappellin, L., F. Loreto, E. Aprea, A. Romano, J. S. del Pulgar, F. Gasperi, and F. Biasioli. 2013. PTR-MS in Italy: A multipurpose sensor with applications in environmental, agri-food and health science. Sensors (Basel) 13:11923-11955.

Correddu, F., A. Nudda, M. G. Manca, G. Pulina, and T. K. Dalsgaard. 2015. Light-induced lipid oxidation in sheep milk: Effects of dietary grape seed and linseed, alone or in combination, on milk oxidative stability. J. Agric. Food Chem. 63:3980-3986.

Cuenca, M., F. Ciesa, A. Romano, P. Robatscher, M. Scampicchio, and F. Biasioli. 2016. Mead fermentation monitoring by proton 
transfer reaction mass spectrometry and medium infrared probe. Eur. Food Res. Technol. 242:1755-1762.

d'Acampora Zellner, B., P. Dugo, G. Dugo, and L. Mondello. 2008. Gas chromatography-olfactometry in food flavour analysis. J. Chromatogr. A 1186:123-143.

Fabris, A., F. Biasioli, P. M. Granitto, E. Aprea, L. Cappellin, E. Schuhfried, C. Soukoulis, T. D. Maerk, F. Gasperi, and I. Endrizzi. 2010. PTR-TOF-MS and data-mining methods for rapid characterisation of agro-industrial samples: Influence of milk storage conditions on the volatile compounds profile of trentingrana cheese. J. Mass Spectrom. 45:1065-1074.

Gallardo-Escamilla, F., A. Kelly, and C. Delahunty. 2005. Influence of starter culture on flavor and headspace volatile profiles of fermented whey and whey produced from fermented milk. J. Dairy Sci. 88:3745-3753.

Garcia-Llatas, G., M. J. Lagarda, F. Romero, P. Abellan, and R. Farre. 2007. A headspace solid-phase microextraction method of use in monitoring hexanal and pentane during storage: Application to liquid infant foods and powdered infant formulas. Food Chem. 101:1078-1086.

Havemose, M. S., P. Justesen, W. L. P. Bredie, and J. H. Nielsen. 2007. Measurement of volatile oxidation products from milk using solvent-assisted flavour evaporation and solid phase microextraction. Int. Dairy J. 17:746-752.

Havemose, M. S., M. Weisbjerg, W. Bredie, H. Poulsen, and J. Nielsen. 2006. Oxidative stability of milk influenced by fatty acids, antioxidants, and copper derived from feed. J. Dairy Sci. 89:1970-1980.

Hedegaard, R., D. Kristensen, J. Nielsen, M. Frost, H. Ostdal, J. Hermansen, M. Kroger-Ohlen, and L. Skibsted. 2006. Comparison of descriptive sensory analysis and chemical analysis for oxidative changes in milk. J. Dairy Sci. 89:495-504.

Jenq, W., R. Bassette, and R. Crang. 1988. Effects of light and copper ions on volatile aldehydes of milk and milk fractions. J. Dairy Sci. $71: 2366-2372$.

Jobson, B. T., and J. K. McCoskey. 2010. Sample drying to improve HCHO measurements by PTR-MS instruments: Laboratory and field measurements. Atmos. Chem. Phys. 10:1821-1835.

Kersiene, M., A. Adams, A. Dubra, N. De Kimpe, and D. Leskauskaite. 2008. Interactions between flavour release and rheological properties in model custard desserts: Effect of starch concentration and milk fat. Food Chem. 108:1183-1191.

Lindinger, W., A. Hansel, and A. Jordan. 1998. On-line monitoring of volatile organic compounds at pptv levels by means of proton- transfer-reaction mass spectrometry (PTR-MS) - Medical applications, food control and environmental research. Int. J. Mass Spectrom. 173:191-241.

Macatelli, M., W. Akkermans, A. Koot, M. Buchgraber, A. Paterson, and S. van Ruth. 2009. Verification of the geographical origin of European butters using PTR-MS. J. Food Compos. Anal. $22: 169-175$

Olivieri, A. C., N. M. Faber, J. Ferré, R. Boqué, J. H. Kalivas, and H. Mark. 2006. Uncertainty estimation and figures of merit for multivariate calibration (IUPAC technical report). Pure Appl. Chem. 78:633-661.

Pang, X. 2015. Biogenic volatile organic compound analyses by PTRTOF-MS: Calibration, humidity effect and reduced electric field dependency. J. Environ. Sci. (China) 32:196-206.

Panseri, S., S. Soncin, L. M. Chiesa, and P. A. Biondi. 2011. A headspace solid-phase microextraction gas-chromatographic massspectrometric method (HS-SPME-GC/MS) to quantify hexanal in butter during storage as marker of lipid oxidation. Food Chem. 127:886-889.

Sanches-Silva, A., A. de Quiros, J. Lopez-Hernandez, and P. PaseiroLosada. 2004. Determination of hexanal as indicator of the lipidic oxidation state in potato crisps using gas chromatography and high-performance liquid chromatography. J. Chromatogr. A 1046:75-81.

Scheidegger, D., G. Larsen, and S. Clara Kivatinitz. 2016. Oxidative consequences of UV irradiation on isolated milk proteins: Effects of hydrogen peroxide and bivalent metal ions. Int. Dairy J. 55:64-71.

Silcock, P., M. Alothman, E. Zardin, S. Heenan, C. Siefarth, P. Bremer, and J. Beauchamp. 2014. Microbially induced changes in the volatile constituents of fresh chilled pasteurised milk during storage. Food Packaging and Shelf Life 2:81-90.

Soukoulis, C., E. Aprea, F. Biasioli, L. Cappellin, E. Schuhfried, T. D Märk, and F. Gasperi. 2010. Proton transfer reaction time-of-flight mass spectrometry monitoring of the evolution of volatile compounds during lactic acid fermentation of milk. Rapid Commun. Mass Spectrom. 24:2127-2134.

Van Ruth, S., A. Koot, W. Akkermans, N. Araghipour, M. Rozijn, M. Baltussen, A. Wisthaler, T. Märk, and R. Frankhuizen. 2008. Butter and butter oil classification by PTR-MS. Eur. Food Res. Technol. 227:307-317.

Zardin, E., P. Silcock, C. Siefarth, P. J. Bremer, and J. Beauchamp. 2016. Dynamic changes in the volatiles and sensory properties of chilled milk during exposure to light. Int. Dairy J. 62:35-38. 